Docent dr Mirko Borisov, pukovnik, dipl. inž.

Vojnogeografski institut,

Beograd
DIGITALNA TOPOGRAFSKA KARTA 1:250 000 - PREMA NATO STANDARDIMA

UDC: $528.425: 004.92$

Rezime:

U radu se iznose iskustva pri izradi i oblikovanju vojne topografske karte razmera 1 : 250 000. Karta se izrađuje u Vojnogeografskom institutu, po NATO standardima i u digitalnom obliku. Iskustva drugih država u kreiranju vojnih topografsko-kartografskih sistema $i$ karata mogu se uporediti sa našim. Postupci izrade $i$ ažuriranja vojnih topografskih karata su informatički podržani uz veliki stepen automatizacije pojedinih faza njihove izrade i osavremenjavanja.

Ključne reči: vojna kartografija, topografska karta, NATO standardi, UTM, simbologija.

\title{
DIGITAL 1:250 000 TOPOGRAPHIC MAP DESIGNED IN ACCORDANCE
} WITH NATO STANDARDS

Summary:

The paper presents the design of the 1:250 000 military topographic map in the Military Geographical Institute (MGI) in accordance with NATO standards and in a digital form. Other states 'experiences in designing military topographic and cartographic systems and maps can be compared with those of the MGI's. The procedures of producing and updating military topographic maps are computer aided while particular phases are automated to a great extent.

Key words: military cartography, topographic map, NATO standards, UTM, symbology.

\section{Uvod}

U sistemu karata koje izdaje Vojnogeografski institut nedostaje topografska karta razmere 1:250 000. Pored toga, određenom analizom može se ustanoviti da karte imaju i mnoge nedostatke, kao što su slaba ili gotovo nikakva primena novih standarda u vojnoj kartografiji. Uspostavljanje interoperabilnosti i novih vojnih standarda veoma je složen, dug i skup posao, a njegovo odlaganje bilo bi neracionalno i neodgovorno, naročito danas kada je naša zemlja u Partnerstvu za mir.

Predmet ovog rada je upravo digitalna topografska karta u razmeri 1:250 000 .
Osnovni cilj je analiza i primena novih standarda, sa težištem na NATO standardima. Topografska karta $u$ razmeri 1:250 000 jedna je od najvažnijih i najčešće korišćenih vojnih topografskih karata u Evropi. Ona je ujedno i osnovna operativna karta u NATO-u.

\section{Topografska karta razmera 1:250000}

Sve zemlje članice NATO-a ili Partnerstva za mir potpisuju međunarodne sporazume o saradnji na području geoprostornih informacija. To znači izradu i razmenu svih listova topografskih karata 


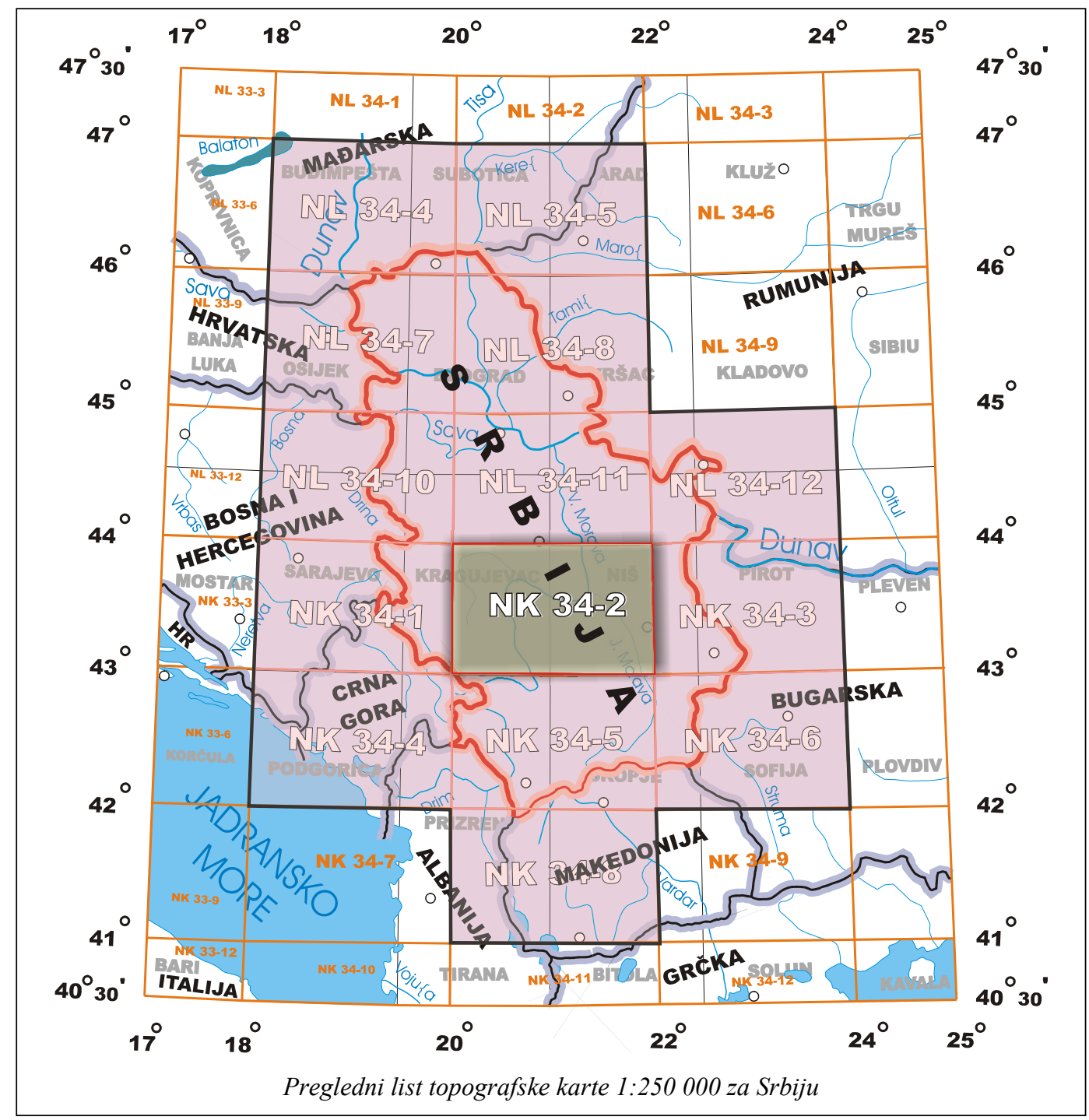

područja susednih država. Pri tome je svaka strana odgovorna samo za podatke na području svoje države. Tako se smanjuju troškovi i vreme izrade topografskih karata, te osigurava potrebna tačnost za podatke izvan granica vlastite države.

U Vojnogeografskom institutu počelo se sa izradom karte 1:250 000. To je projekat Vojna topografska karta razmera 1:250 000, kopnene i aeronautičke (vazduhoplovne) varijante, nazvan JOG
- Joint Operation Graphics. Pri tom, standardi NATO-a dozvoljavaju sadržajnu i vizualnu raznolikost karata u različitim zemljama članicama, ali matematička osnova vojnih topografskih karata mora biti ista. To se, pre svega, odnosi na razmeru i projekciju.

Takođe, postoje objekti i simboli u kartografskom ključu, kao i fenomeni u prirodi, koji nisu mnogo važni ili nisu više aktuelni. Prethodna klasifikacija sadr- 
žaja je prilično neusklađena. To se posebno odnosi na prikaz puteva. Na primer, postoji dilema da li da se zadrži zastarela podela (glavni, regionalni ili lokalni) ili izvede nova klasifikacija puteva, prema tehničkim karakteristikama i kvalitetu.

\section{Projekcija i podela na listove}

Radi racionalizacije, modernizacije, postizanja interoperabilnosti, te ispunjavanja standarda NATO (STANAG - Standardization Agreement) potrebno je preći na novi geodetsko-kartografski sistem. Izrada topografske karte razmera 1:250 000 prema novim standardima obuhvata usklađivanje $i$ ispunjavanje određenih normi i kartografskih specifikacija. To su:

- kartografska projekcija - UTM,

- referentni elipsoid - WGS 84,

- visinska osnova - srednji nivo mora (Jadransko more),

- koordinate - pravougle i geografske,

- referentni sistem - vojna kartografska mreža (grid),

- područje Srbije - 14 listova (slika),

- format listova $-2^{\circ} \times 1^{\circ}$.

\section{Sadržaj topografske karte}

Sadržaj topografske karte 1:250000 uslovljen je, pre svega, njenom vojnom namenom. Nova rešenja treba da zadovolje prvenstveno vojne potrebe. Međutim, osim te osnovne namene, ona može da zadovolji i potrebe drugih korisnika. Zbog toga je koncipirana kao pregledna topografska karta. Takođe, na prikaz i izbor sadržaja karte utiču različiti faktori privrednih i infrastrukturnih promena na terenu. Sadržaj vojne topografske karte u razmeri 1:250000 obuhvata: reljef, hidrografsku mrežu i objekte, vegetaciju, naseljena mesta, komunikacije i objekte na njima (putevi, železnice, mostovi, tuneli), državnu granicu i objekte, vojne objekte i infrastrukturu, trigonometrijske i nivelmanske tačke i toponime i brojčane podatke.

Topografska karta razmere 1:250000 izrađuje se na osnovu postojećih kartografskih materijala. Osnovni izvori su geobaza podataka PTK 1:300 000, digitalna topografska karta 1:200 000 i digitalna vazduhoplovna vojna karta 1:200 000. Pomoćni izvori podataka predstavljaju topografske karte krupnije razmere i raspoloživi statistički izvori (popis stanovnika, podaci javnih preduzeća iz oblasti infrastrukture i dr.).

Pored izbora sadržaja topografske karte u razmeri 1:250000 i utvrđivanja koncepcije njegovog prikaza javila se potreba da se sagleda njena celina, a posebno legenda. Vanokvirni sadržaj ove karte jedinstven je za sve listove i sadrži:

- naziv karte, naziv lista, oznaku i broj izdanja,

- nazive i oznake veznih listova,

- upozorenja o zabrani kopiranja i umnožavanja,

- podatke o kartografskim izvorima, - podatke o izdavaču i godini izdanja,

- preglednu skicu s položajem veznih listova,

- oznaku kvadrata 100×100 km vojne UTM mreže,

- oznaku tajnosti i

- nazive na srpskom i engleskom.

Sadržaj topografske karte 1:250000 vremenom će se dopunjavati, ne samo postojećim kartografskim podacima krupnije 
razmere, već će se koristiti aerofoto i satelitski snimci. Ubuduće se može očekivati automatska kartografska generalizacija i brža dopuna iz krupnijih razmera, kao i izvođenje sadržaja geografskih karata sitnijih razmera (1:500 000 i 1:1 000 000).

\section{Postupak izrade karte}

Izrada digitalne topografske karte $\mathrm{u}$ razmeri 1:250 000 obavlja se u GIS okruženju. Nakon izbora i georeferenciranja digitalnih izvora podataka (većina izvora podataka u Vojnogeografskom institutu imaju digitalnu formu) u novi koordinatni sistem (UTM - WGS84), pristupilo se obradi i modelovanju sadržaja u jedinstvenoj geobazi podataka za topografsku kartu 1:250 000. Vizualizacija podataka zasnovana je na novoj simbologiji, odnosno primeni biblioteke znakova iz softvera ArcGIS, a urađeni su i novi kartografski simboli. Simbologija je direktno implementirana u geobazu i omogućila željeni prikaz podataka.

Posle iscrtanog sadržaja karte, obavljena je korektura i, na kraju, verifikacija karte na probnom otisku. Nakon toga generisani su postscript fajlovi za izradu filmova (izvaci boja - cmyk) i pristupilo se filmovanju, odnosno fotoosvetljavanju postscript fajlova. Tiražna štampa karte izrađuje se u šest boja za kopnenu varijantu i sedam boja za vazduhoplovnu varijantu.

\section{Zaključak}

Sve države u tranziciji su u sličnom položaju, pa nastoje da se približe praksi i standardima zapadnih zemalja u izradi vojnih topografskih karata. I u Srbiji se, pristupanjem Partnerstvu za mir, pojavljuje potreba i obaveza da se izradi topografska karta razmere 1:250 000 prema novim standardima. Postupkom standardizacije postiže se harmonizacija i usklađivanje sadržaja topografskih karata, koje najčešće koriste komande, vojne jedinice, ali i drugi organi i državne službe (vladine organizacije, instituti i dr.).

\section{Literatura:}

[1] Geographic service of armed forces of the Czech Republic (2006): Military geographic service and military topographic institute Dobruška.

[2] Borisov, M. (2005): Topografsko-kartografski sistem prema novim vojnim standardima, Stručni rad, Vojnotehnički glasnik br. 3-4, Beograd, str. 315-325.

[3] http://www.maptrax.com.au/topographicmaps.htm http://www.defence.gov.au/digo/digo/ProductVMap.htm

[4] STANAG 3600, (2000): Topographical Land Maps and Aeronautical Charts 1:250000 for Joint Operations, North Atlantic Treaty Organization, Military Agency for Standardization. 


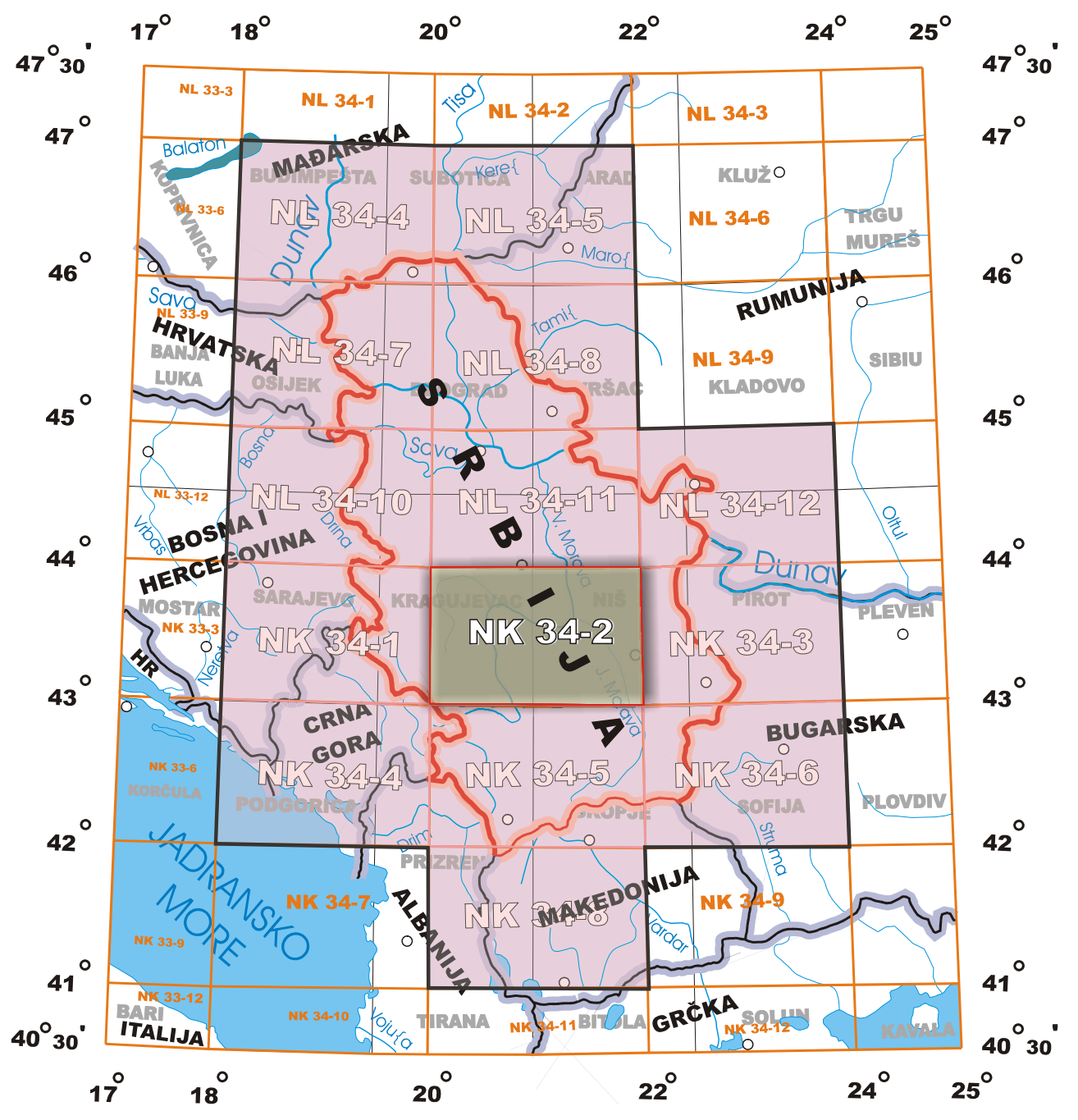

Pregledni list topografske karte 1:250 000 za Srbiju 